\title{
A criação do Instituto Nacional de Cinema Educativo na Era Vargas: debates e circulação de ideias
}

The creation of the National Institute of Educational Cinema in the Era Vargas: debates and circulation of ideas

La creación del Instituto Nacional de Cine Educativo en la Era Vargas: debates y circulación de ideas

\author{
Lara Rodrigues Pereira \\ Universidade Federal de Santa Catarina (Brasil) \\ https://orcid.org/0000-0002-3294-460X \\ http://lattes.cnpq.br/0174305471365523 \\ lararp81@gmail.com
}

\begin{abstract}
Resumo
$\mathrm{O}$ artigo que segue trata da criação do Instituto Nacional de Cinema Educativo (INCE), órgão gestado durante o primeiro governo Vargas e que foi inaugurado em 1936. A escolha do administrador do INCE, Roquette-Pinto, foi contextualizada durante o texto, algo que ajudou a explicar certos aspectos científicos alocados nos filmes do Instituto. Trago como fontes, trechos do Decreto-lei n. 21.240 de abril de 1932 que instituiu o órgão, artigos assinados pelo cineasta Humberto Mauro na revista A Cena Muda, recortes de discursos de autoridades políticas e pensadores da educação do período. Esses documentos apontaram para o alinhamento entre cinema educativo e propaganda política, além de trazerem à tona elementos vinculados a uma moral religiosa católica, cuja premissa foi moldar as narrativas cinematográficas produzidas por todo o cinema brasileiro do período, sobretudo o educativo.
\end{abstract}

Palavras-chave: INCE. Cinema educativo. Propaganda Política. Era Vargas. 


\begin{abstract}
This article deals with the creation of the National Institute of Educational Cinema (INCE), an organ created during the first Vargas government and inaugurated in 1936. The choice of the administrator of INCE, Roquette-Pinto, was contextualized during the text, something that helped to explain certain scientific aspects in the films of the Institute. The sources, excerpts from Decree-Law no. 21,240 of April of 1932 that instituted the organ, articles signed by the filmmaker Humberto Mauro in the magazine A cena Muda, cuts of speeches of political authorities and thinkers of the education of the period. These documents pointed to the alignment between educational cinema and political propaganda, as well as bringing to the surface elements linked to a Catholic religious morality whose premise was to shape the cinematographic narratives produced by the entire Brazilian cinema of the period, especially the educational one.
\end{abstract}

Keywords: INCE. Educational cinema. Political Propaganda. Age Vargas.

\title{
Resumen
}

El artículo que sigue trata de la creación del Instituto Nacional de Cine Educativo (INCE), órgano gestado durante el primer gobierno Vargas y que fue inaugurado en 1936. La elección del administrador del INCE, Roquette-Pinto, fue contextualizada durante el texto, algo que ayudó a explicar ciertos aspectos científicos acocados en las películas del Instituto. Traigo como fuentes, trechos del Decreto-ley n. 21.240 de abril de 1932 que instituyó el órgano, artículos firmados por el cineasta Humberto Mauro en la revista A Cena Muda, recortes de discursos de autoridades políticas y pensadores de la educación del período. Estos documentos apuntaron a la alineación entre cine educativo y propaganda política, además de traer a la superficie elementos vinculados a una moral religiosa católica cuya premisa fue moldear las narrativas cinematográficas producidas por todo el cine brasileño del período, sobre todo el educativo.

Palabras clave: INCE. Cine educativo. Propaganda Política. Era Vargas. 


\section{Introdução}

A inauguração do Instituto Nacional de Cinema Educativo (INCE) ocorreu durante a gestão do Ministro Gustavo Capanema frente ao Ministério de Educação e Saúde, na primeira gestão Vargas. Era 1936 e o Ministro escolheu Edgar Roquette-Pinto para a direção administrativa do Instituto. O escolhido, além de médico e antropólogo, era um entusiasta do emprego das novas tecnologias para a educação, sobretudo o rádio e demais recursos audiovisuais. A função do Instituto era a de documentar, por meio de filmes, as manifestações culturais, científicas, cívicas e a História do Brasil, para difundi-las na rede escolar. RoquettePinto, que foi o gestor do INCE de $1936^{1}$ até 1947 , vinha trabalhando com a perspectiva do cinema como registro científico por quase duas décadas, por meio de estudos etnográficos e filmando expedições aos confins do Brasil. Nestas incursões teve como atores de seus filmes os grupos indígenas isolados que visitou assim como a exuberante fauna e flora brasileiras.

No intuito de compreender melhor a escolha de Roquette-Pinto para a direção do INCE, torna-se importante percebê-lo como indivíduo cuja trajetória vincula-se ao serviço público, já que era portador de virtudes e conexões pertinentes àquele espaço social e também político (BOURDIEU, 2006). Para Schvarzman (2004), Roquette-Pinto construiu carreira respeitada como pesquisador e educador em função do longo período que esteve na direção do Museu Nacional, onde assumiu como missão principal o mapeamento da gênese da nação, por meio da investigação de etnias diversas.

$\mathrm{O}$ diretor do INCE iniciou sua trajetória científica no limiar do século XX, quando era estudante de Medicina. Na vida acadêmica estabeleceu contato com as teorias pertinentes à área de formação, mas também aprofundou seu interesse por Literatura e Antropologia. Sua curiosidade sobre o Brasil não se limitava às moléstias tropicais convertidas em epidemias, mas à compreensão da formação, ocupação territorial, e principalmente do que seria o povo brasileiro. Talvez tais predicados tenham sido o legado de autores como Euclides da Cunha, nas aventuras pelos sertões de Canudos, e Goethe, nos escritos sobre a humanidade, dos quais Roquette-Pinto era ávido leitor (SCHVARZMAN, 2004).

A curiosidade científica de Roquette-Pinto, alinhada com o positivismo em evidência na época, fez com que se unisse à expedição de Rondon em 1912, lançando mão do cinematógrafo, da fotografia e do rádio para registrar e informar a capital sobre as populações e paisagens pelas quais passou. Nessa jornada, ele travou contato mais íntimo com a Antropologia, no intuito de compreender os nativos, suas relações entre si e com a natureza, enfatizando a importância do registro por meio das imagens. Observou, naquela expedição, que o Brasil era formado por dimensões distintas quando proferiu a sentença: "brasileiro é brasileiro e índio é índio". Frases como esta norteariam retratos feitos de povos indígenas pelas produções do INCE, a exemplo de Bandeirantes, de 1940. A imagem do índio dócil, puro, infantilizado ${ }^{2}$ e mero figurante do movimento das bandeiras alinhava-se aos textos de antropologia lidos por Roquette-Pinto na época da parceria com Rondon. De acordo com Schvarzman (2004, p. 99), "no contato com o primitivo, percebeu a diferença, e não desejava que os índios fossem assimilados ao povo brasileiro. Pregava o respeito e a manutenção de seu modo de vida e seu espaço."

\footnotetext{
${ }^{1}$ Percebe-se que a partir de 1939, com a criação do DIP, o INCE perdeu recursos para a produção de filmes que foram destinados ao segmento específico de Propaganda (MORETTIN, 2013).

${ }^{2}$ Nesse ponto é preciso diferenciar a imagem do índio, no filme Bandeirantes do INCE, em relação ao índio no texto canônico da literatura romântica brasileira, O Guarani, de José de Alencar. Enquanto os índios do INCE são retratados como infantis, a despeito da idade e, em decorrência disso, necessitados da tutela da população branca (seja de Anchieta ou dos bandeirantes), o índio de Alencar, protagonizado pela figura de Peri, aproxima-se mais do estereótipo do bom selvagem de Rousseau, que, embora seja romantizado em sua profunda pureza, teria certo poder de decisão e capacidade para gerir a própria vida.
} 
Os registros das expedições com Rondon associados a outros filmes científicos, culturais e institucionais formavam o acervo do Museu Nacional, no âmbito da direção de Roquette-Pinto em 1926. Lá ele organizou a maior coleção de filmes científicos do Brasil, muitos dos quais vieram a inspirar as produções do INCE. Em um dos primeiros cinejornais do INCE, cujo tema foi a inauguração das instalações da Rádio Sociedade, em 07 de setembro de 1936, Capanema discursou homenageando Roquette-Pinto.

Agradeço a Roquette-Pinto, que dando a sua vida um sentido de sabedoria e beleza trouxe a educação dos brasileiros dois poderosos instrumentos: o rádio e o cinema, cabe-lhe a iniciativa da doação, justo também que lhe caibam os maiores agradecimentos. Dr. RoquettePinto é um de nossos mais puros patriotas, um de nossos maiores homens de cultura, pode ser considerado sobre muitos aspectos como um feiticeiro que pratica diante de um auditório maravilhado as artes que recolheu do convívio dos livros e da natureza, apenas se difere dos demais feiticeiros quando ensina ao público a infinidade dessas artes. (DISCURSO DE CAPANEMA, 1936).

Capanema apresentou o médico como um operador de "feitiços" científicos dados por meio do rádio e do cinema, equipamentos que serviram para mostrar o conhecimento dos livros e da natureza, nos quais residiria a essência da brasilidade. Nota-se que o Brasil de Capanema a ser construído, ensinado e aprendido, era resultado das tradições - "gigante pela própria natureza", repleto de riquezas, catolicismo, valores da família patriarcal e propriedade, combate ao comunismo - associadas a certas inovações (cinema, rádio, urbanização), cabendo a Roquette-Pinto fomentar esse projeto.

A pedido de Roquette-Pinto, em 1936, Humberto Mauro foi contratado como diretor técnico do INCE, cargo que ocupou por mais de vinte anos. O resultado da longevidade de Mauro no cargo foi a produção de cerca de 357 filmes, dos quais a maior parte possuía tempo reduzido, entre cinco e vinte minutos, para que fossem encaixados no horário escolar. $\mathrm{O}$ cineasta já possuía carreira consolidada na área cinematográfica como diretor e produtor de vários títulos. Um de seus filmes mais reconhecidos, O Descobrimento do Brasil ${ }^{3}$, foi lançado pela Distribuidora de Filmes Brasileiros (DFB) e produzido com subsídios do Instituto do Cacau da Bahia, em 1937. Humberto Mauro foi escolhido para o cargo porque possuía um bom relacionamento com Roquette-Pinto, seu conhecido desde os tempos dos estúdios Cinedia. Lá dirigiu vários filmes educativos sob encomendo do médico para o Museu Nacional.

Mineiro como o ministro Capanema, Humberto Mauro partilhava das influências modernistas, fortes na época, uma vez que sua principal busca, desde as primeiras produções, era capturar a essência da brasilidade rural (SCHVARZMAN, 2004). Suas tramas mineiras, mesmo quando travestidas de romances, tratavam das relações do homem com a terra. Tal panorama seria alterado com sua mudança para a capital federal, onde privilegiaria narrativas mais urbanas como Favela dos meus amores ${ }^{4}$. O reencontro com a brasilidade interiorana, no entanto, foi reeditado pela atuação no INCE em filmes como Bandeirantes (em que retrata a ocupação do interior a partir do litoral) Barão do Rio Branco e Euclides da Cunha, responsáveis pelo alcance do território (no primeiro caso) e pela caracterização da população sertaneja brasileira (no segundo caso).

O cineasta mineiro chegou ao Rio de Janeiro no início dos anos 1930, onde trabalhou em produtoras como a citada Cinedia, que sobrevivia, em grande medida, devido à produção de filmes subsidiados pelo Estado, cujas temáticas já podiam ser enquadradas como educativas.

\footnotetext{
${ }^{3}$ O DESCOBRIMENTO do Brasil. Direção de Humberto Mauro. Brasil: DFB, 1937. (80 min.), DVD, P\&B.

${ }^{4}$ FAVELA dos meus amores. Direção de Humberto Mauro. Brasil: Brasil Fox Filme, 1935.
} 
O encontro com Roquette-Pinto se deu, quando este, ainda à frente do Museu Nacional, encomendou filmes para compor seu acervo institucional, muitos dos quais foram dirigidos por Humberto Mauro. O desligamento de Muro da Cinedia ocorreu em 1933, e, anos mais tarde, foi convidado por Roquette-Pinto para assumir a responsabilidade de dirigir o segmento técnico do INCE. O cineasta foi visto como funcionário dedicado pela vasta produção e longevidade no órgão, superando a permanência de Pinto, que se desligou em 1947.

Para compreender a aliança entre Roquette-Pinto e Humberto Mauro no INCE, é preciso identificá-los como sujeitos que compartilharam interesses para além do ambiente de trabalho. O médico teve no cineasta um aplicado aprendiz: ensinou-lhe rudimentos do tupiguarani e contava-lhe suas aventuras ao lado de Rondon, mapeando populações nativas e, até então, isoladas (SCHVARZMAN, 2004). Tais ensinamentos foram incorporados à curiosidade que o cineasta mineiro nutria pelo Brasil, posteriomente revertidos em narrativas cujo mote costumava ser o povo, o território e a natureza da nação. A afinidade existente entre Humberto Mauro e Roquette-Pinto ultrapassou o ambiente corporativo, uma vez que mesmo nas produções assinadas pelo primeiro fora do INCE, havia, em grande medida, a contribuição do segundo, que pode ser observada em títulos como O Descobrimento do Brasil, sobre a chegada dos portugueses e Argila $^{5}$, filme que tratava da cultura marajoara.

A respeito de Roquette-Pinto, Humberto Mauro afirmava: "Há muita coisa nos filmes do INCE que é minha. O Roquette mandava fazer o Carlos Gomes. Está bem, vamos fazer. Agora, quando tinha interpretação da música, era minha, se saía bom, saiu, se saía ruim, saiu também. Era a imaginação minha." (VIANY, 1978, p. 31). Nesse ponto, é possível perceber que ele acatava as determinações de Roquette-Pinto, o que não excluía sua liberdade de ação e de criação no órgão. Essa parceria tinha em comum a ideia de que seria preciso usar o cinema para exaltar a cultura e a História brasileira, ensinando-a para o maior número possível de pessoas. Essa premissa encontrava eco no Decreto-Lei 21.240: "Considerando que os filmes educativos são material de ensino, visto permitirem assistência cultural, vantagens especiais de atuação direta sobre as grandes massas populares e, mesmo, sobre analfabetos." (BRASIL, 1932).

\section{Escritos de Humberto Mauro na Revista A Cena Muda}

Humberto Mauro foi, durante o tempo em que atuou no INCE, colunista da revista especializada em cinema A Cena Muda. A revista, que começou a ser publicada em 1921, teve sua última edição em 1955, e durante todo esse período sua premissa era de informar aos leitores sobre os modos de vestir e o comportamento de grandes astros e atrizes que compunham o Star System (sistema de grandes estúdios). Cabia à revista, assim como a outras publicações do gênero, propagandear o estilo de vida das celebridades, lançando moda baseada nas roupas que vestiam, nos cigarros que fumavam, nos produtos de higiene e beleza que usavam (ADAMATTI, 2008). Na publicação, entretanto, também havia demanda para textos que falassem sobre o cinema nacional, englobando o universo das estrelas e divulgando os esforços da indú stria local.

No espaço que ocupava no periódico, o cineasta, em diversas circunstâncias, propagandeava os feitos do INCE, tratando-o como legítimo instrumento criado pelo Estado brasileiro no combate às falhas do sistema educacional. $\mathrm{O}$ fato de Humberto Mauro ser funcionário do órgão era indício de conflito de interesses, e o resultado disso é que suas colunas exaltavam os feitos do INCE e, consequentemente, do governo que o criara, furtando-se a críticas e transformando seus textos em um meio de difusão dos ideais do Estado Novo. Em um artigo assinado por Humberto Mauro na revista, datado de 12 de outubro de 1943, merece destaque o trecho que anuncia a missão da coluna, que seria

\footnotetext{
${ }^{5}$ ARGILA. Direção de Humberto Mauro. Brasil: Vita Filmes, 1940. (103 min.), DVD, P\&B.
} 
regular. Nele, o articulista afirma que a intenção do espaço no periódico era de mapear a situação do cinema nacional, compreendendo seus avanços e falhas, e contribuindo, assim, para que evoluísse e ajudasse a consolidar a nação.

Queremos apontar o que já se fez pelo cinema no Brasil. O que se realiza nesse momento e aquilo que ao nosso entender deve se projetar para o futuro, tendo em mira cooperar pela obra nacional do cinema, cujos rumos pensamos precisam por todos ser indicados, para maior segurança em suas realizações. (MAURO, 1943, p. 22).

No mesmo texto, Humberto Mauro expandiu a discussão, saindo do eixo do cinema como arte, e migrando para as condições de crescimento da indústria nacional cinematográfica no então governo, que, a seu ver, era patriótico. Tais condições diziam respeito ao desenvolvimento industrial brasileiro, ou à facilidade de importações dos itens necessários para suprir setores específicos da cinematografia.

Falar sobre cinema nos é muito grato. Empenhados nele há mais de quinze anos jamais desanimamos na caminhada que por certo levará à criação final e completa dessa arte e dessa indústria em nossa terra, tão necessitadas delas em razão de suas condições atuais de progresso, geográficas e notadamente do caráter de seu povo. A criação do Instituto Nacional do Cinema Educativo é o índice eloquente da convicção a que chegou a administração pública brasileira da solução inadiável desse problema, que trará consigo a de tantos outros, direta ou indiretamente ligados a todos aqueles requisitos que denotam a vida civilizada das grandes nações, ao número das quais pertencemos sem favor e por todos os títulos. Se bem que ainda não estejamos habilitados industrialmente para nos abastecermos do aparelhamento e da matéria prima necessária à mão de obra dispensando a importação a que isso nos leva, não tardará o dia da independência siderúrgica. Mas enquanto não ultimamos essa etapa difícil da nossa evolução econômica, podemos ir realizando até em grande escala, a produção dos nossos filmes. Não nos faltará como nunca faltou, quando os transportes marítimos e aéreos se processam normalmente, o produto que nos vem do estrangeiro, muita vez isento de maiores ônus alfandegários, quando a visão patriótica do Governo vê aí a melhor maneira de facilitar o esforço produtivo dos brasileiros. (MAURO, 1943, p. 22).

Além da preocupação com a indústria cinematográfica, o cineasta engrossou o coro, corrente na época, clamando por independência nacional na indústria siderúrgica. Essa "independência" seria conquistada no ano de 1946, quando a Cia. Siderúrgica Nacional (CSN) passou a operar. Quando elogiou a atuação do governo brasileiro no fomento da indústria cinematográfica, Humberto Mauro referia-se aos resultados do Decreto-lei 21.240, de abril de 1932, que definia (BRASIL, 1932) que a importação do filme virgem, negativo e positivo, deveria ser facilitada, porque era matéria prima indispensável ao surto da indústria cinematográfica no país.

A unidade pela qual o cineasta clamava acaba sendo um reflexo dos intentos políticos estadonovistas do período: a ideia de que a união nacional seria dada por meio da consolidação da brasilidade, construída pelas diferenças, desde que virtuosas, que perpassavam o país. 
Um bom caminho a seguir seria o "Documentário". Um grande filão a explorar. Achamos que o documentário seria o cinema brasileiro para o mundo. Mesmo o filme de enredo deve ter qualquer coisa de verdade. $O$ documentário que nós imaginamos seria a nova marcha para uma nova modalidade no cinema, com imensas possibilidades, oferecendo arte puríssima e uma forma elevada de conhecimentos que os cineastas ainda não lançaram mão. Há muitos anos que o Documentário nos empolga e sempre que temos oportunidade lembramos as suas vantagens aos cinematografistas patrícios. Seria fixar em nossos filmes simplesmente a realidade - dramas e comédias - representados por seus personagens reais ou a natureza vista em função do homem que nela se movimenta. Nada de se filmar o jangadeiro de Paquetá ou da Barra da Tijuca no estúdio com palmeirinhas de papel. Seria a rigor a filmagem bem ao vivo. (MAURO, 1942, p. 22).

O cineasta clamou por maior criação de documentários pelos produtores do Brasil, e não se furtou a criticar a indústria cinematográfica, seja a nacional ou a estrangeira, em função de seus arroubos de individualismo. Ele considerava necessário produzir um cinema legitimamente brasileiro e, para tanto, seria preciso dedicar-se a histórias que envolvessem a população, a coletividade, e não crônicas do peculiar, conforme podia ser visto no cinema estrangeiro e até mesmo no nacional. Suas ideias estavam em plena consonância com o que Vargas declarou em 1940: que o Estado Novo, para ser democrático de fato, deveria se contrapor às desagregações e heterogeneidades, bem como colocar-se contra particularismos (CAPELATO, 2008).

Humberto Mauro afirmava ser "grande admirador dos documentários que teriam permitido maior liberdade de ação aos cineastas, tolhidos pelo comercialismo excessivo dos filmes normais." (VIANY, 1978, p. 31). Além do elogio ao gênero "documentário", o cineasta do INCE acabou criticando a indústria cinematográfica, por estipular o gênero "ficcional", de longa-metragem, como paradigma de produção e comercialização. Seu posicionamento de crítica aos produtos padronizados da indústria do cinema, acabou por promover elogio ao Estado, que viabilizava a produção e divulgação de materiais desprezados pela indústria cinematográfica privada. Sua fala, mais uma vez, estava em consonância com a legislação disponível na época, "considerando que o filme documentário, seja de caráter científico, histórico, artístico, literário e industrial, representa, na atualidade, um instrumento de inigualável vantagem, para a instrução do público e propaganda do país, dentro e fora das fronteiras." (BRASIL, 1932). A propaganda política operada pelo cineasta, em defesa das estratégias do Estado brasileiro comandado por Vargas, ficou evidente na sua coluna na $A$ Cena $M u d a$, assim como esteve nitidamente presente em alguns dos filmes do INCE. Filmes que puderam ser lidos como difusores das boas relações (permeadas por representações da História brasileira) entre agentes do Estado e a população.

\section{Debates e discussões sobre os limites morais do cinema: por um cinema de virtudes!}

O reconhecimento do cinema como entretenimento de massas e difusor de ideias foi um fenômeno que marcou o início do século XX, não só na Europa e na América do norte, mas também no Brasil. No âmbito nacional a vocação educativa do cinema já era reconhecida e colocada em prática por meio de ações como os registros cinematográficos de expedições orquestradas pelo marechal Cândido Rondon. Entretanto, assim como o fascínio pelo potencial didático do cinema crescia, cresciam também desconfianças sobre 
seus usos. Eram constantes as críticas contra um "cinema fútil”, ou seja, comercial, que mesmo inadvertidamente, ensinasse valores inadequados ou difundisse conhecimentos considerados incorretos (ROSA, 2008). O amplo consumo das fitas hollywoodianas promovia uma outra ameaça para a educação nacional: os brasileiros veriam a cultura norte-americana, massivamente, representada pelo cinema, enquanto a brasileira não. Em função disso os especialistas, como Humberto Mauro, acreditavam que a defesa de valores nacionais para o cinema, ajudaria na construção da cidadania e identidade nacional.

A preocupação com a pouca representação do Brasil e dos brasileiros, por meio de filmes, ultrapassou os debates das décadas e 1920 e 1930. Humberto Mauro, em seus textos na revista A Cena Muda, conforme visto anteriormente, criticava certa tendência de "americanização" do cinema brasileiro, enfatizando a importância de serem realizadas experiências cinematográficas que buscassem retratar as características nacionais, isso por que o cinema Hollywoodiano já ocupava as salas de exibição brasileiras desde a década de 1920 (SALIBA, 2003). É preciso ressaltar que o artigo assinado por Humberto Mauro, compilado a seguir, data de 1943, logo, a lei de censura cinematográfica brasileira já estaria em vigor há mais de dez anos. Contudo, as questões concernentes à melhoria na produção cinematográfica nacional não estavam resolvidas com a concepção e aplicação do decreto de 1932, tampouco as questões relativas à identidade das produções nacionais.

Os filmes estrangeiros de um modo geral, habituaram-nos a um cinema convencional, para fins comerciais e daí, sem dúvida, essa preocupação que aqui já existe de se fazer filmes brasileiros em desacordo com nossa realidade, em conflito evidente com a vida que aqui levamos. Justifica-se que até certo ponto que o filme americano seja luxuoso, porque nos Estados Unidos a riqueza está quase sempre à vista de toda gente. Pretender imitá-los no Brasil seria condenável, além do mais porque nos falta para isso os recursos necessários... Mas, se o cinema estrangeiro já nos habituou ao luxo e à variedade nas produções estamos certos de que ainda não nos roubou o entusiasmo natural que temos por tudo aquilo que seja uma representação fiel daquilo que somos e que desejamos ser. (MAURO, 1943, p. 27).

Os supostos maus exemplos oriundos dos filmes ficcionais eram uma constante preocupação no período, pois acreditava-se que poderiam ensinar maus hábitos e comportamentos, portando-se de maneira "perversa, capazes de subverter a ordem estabelecida." (FERRO, 2010, p. 159). Em uma sociedade marcada pela égide patriarcal, como a brasileira, filmes como $O$ anjo $a z u l^{6}$, no qual uma cantora de cabaré seduz e "desvirtua" um professor moralista, poderiam ser fruto de grande descontentamento. Assim como as críticas satíricas feitas pelo Carlitos de Chaplin, aos abusos operados, contra a população pobre, pelas elites e a polícia. A preocupação com os ensinamentos transmitidos, por meio dos filmes, estava ligada à sua potência, por que, seus críticos acreditavam que "a mesma linguagem que revelava, dava consciência, poderia mentir e manipular." (NÓVOA, 2009, p. 176).

O pavor com relação a possíveis deturpações de valores, operadas pela indústria de Hollywood, devia-se ao fato de que a censura cinematográfica até 1934, naquele país, não estava plenamente estabelecida, o que permitia com que fossem feitos filmes como Scarface ${ }^{7}$, em que o protagonista apaixona-se pela própria irmã, Terra de Paixões ${ }^{8}$ cuja protagonista era

\footnotetext{
${ }^{6}$ O ANJO azul. Direção de Josef von Sternberg. Alemanha: Universum Film S.A., 1930. (100 min.), DVD, P\&B.

${ }^{7}$ SCARFACE. Direção de Howard Hawks. EUA: Universal, 1932. (94 min.), DVD, P\&B.

${ }^{8}$ TERRA de Paixões. Direção de Victor Fleming. EUA: MGM, 1932. (83 min.), DVD, P\&B.
} 
uma prostituta, e $O$ último chá do General Yenn ${ }^{9}$, no qual há relação amorosa inter-étnica entre o general chinês e uma missionária americana. Apenas a partir de 1934, por intermédio de reivindicações de membros de igrejas, associações de moradores e ligas familiares, houve a estipulação de critérios rígidos com relação a representação de cenas de nudez, insinuações sexuais, consumo de drogas, relações inter-étnicas e violência ${ }^{10}$ no cinema norte-americano.

Além da dicotômica relação de entusiasmo e receio causada pelo poder influenciador do cinema, a crise na organização jurídica liberal brasileira, realidade experimentada na década de 1920, fez com que a intelligentsia ${ }^{11}$ da época, passasse a clamar por uma maior participação do Estado em todos os segmentos da vida do cidadão. A influência estatal deveria compreender a formação e instrução ${ }^{12}$ dos cidadãos, atribuídas à educação (GOMES, 1998). Em virtude disso, observam-se no início da década de 1930, constantes discussões que envolviam o protagonismo do Estado frente aos processos educativos (SALIBA, 2003). Essas discussões pendiam para a ideia de que, ao Estado, cabia orquestrar a simbiose entre cinema e educação, uma vez que "o cinema deveria exercer uma função educativa, pois era um instrumento para isso, portanto, seria preciso apoderar-se dele." (FERRO, 2010 p. 160). Para tanto, o Estado precisaria considerar, sobretudo, aspectos cívicos e científicos conforme professou Joaquim Canuto Mendes de Almeida ${ }^{13}$.

A educação é hoje uma função do Estado, embora acidental. O Estado pode, pois, em nome da educação, intervir no cinema. No momento atual deve intervir (...). O Estado não deve fazer fitas para pregar a moralidade, mas, para sistematicamente propagar ensinamentos de higiene, economia doméstica, processos racionais de agricultura, indústria ou comércio, conceitos científicos gerais e especializados, cultura artística, o amor às virtudes da caridade e solidariedade social, a coragem moral e física, à saúde do corpo e do espírito, à pátria e ao progresso, à disciplina e à ordem. (ALMEIDA, 1931, p. 141).

\footnotetext{
${ }^{9}$ O ÚLTIMO chá do General Yen. Direção de Frank Capra. EUA: Columbia Pictures, 1933. (88 min.), DVD, P\&B.

${ }^{10}$ Essa norma ficou conhecida como Código Hays, nome do advogado que redigiu o documento. Os estúdios passaram a submeter roteiros e copiões aos censores até 1966, contudo, a rigidez na aplicação das normas foi maior a partir de sua criação, em 1934, e durante as décadas de 1940 e 1950. Exemplos do que passou a ser proibido nos filmes hollywoodianos com o Código Hays: Representar membros do clero, sejam protestantes ou católicos, com vilania; nudez parcial, já que a total já era proibida; escravidão de pessoas brancas; consumo de drogas ilícitas, relacionamentos amorosos entre indivíduos do mesmo sexo ou de etnias distintas; incesto; os vilões nunca poderiam triunfar; beijos deveriam ser discretos e rápidos. Apesar da normatização imposta pelo código ter alcançado sucesso considerável nas décadas de 1930, 1940 e 1950 , houve momentos em que tais normas foram burladas a exemplo das cenas que abordavam consumo de drogas e abuso sexual no filme A marca da maldade dirigido por Orson Welles em 1958, ou nas cenas erotizadas da atriz Jane Russel no filme O Proscrito, dirigido por Howard Hughes em 1943.

${ }^{11}$ Termo que indica a intelectualidade de uma sociedade em período específico. A primeira metade do século XX foi marcada pelo "autorreconhecimento de uma intelectualidade como portadora da civilização, afirmando-se detentora de uma missão social e política: explicar o país, apontando problemas, propondo soluções e elaborando projetos para o futuro da nação" (GONTIJO, 2007, p. 318). No que diz respeito ao Ministério Capanema, essa premissa estava incutida na elaboração de um plano educacional baseado em reformas que tinham por objetivo incluir parte representativa da população discente em cursos que visavam a instrumentalização para o trabalho. Além disso, houve um substancial investimento em segmentos ministeriais que visavam, sobretudo, a mediação cultural entre Estado e população estudantil.

${ }^{12}$ É preciso ressaltar a diferença entre formação e instrução operada na época, percebendo-se na primeira o caráter cidadão e na segunda, sobretudo, a instrumentalização intelectual

${ }^{13}$ Canuto Mendes nasceu em 1906 e foi um pesquisador do cinema e cineasta que engrossou o coro que pleiteava mais espaço para a produção e exibição de filmes nacionais. No corrente artigo foram usados, como fontes, trechos de sua obra Cinema contra cinema: bases gerais para um esboço de organização do cinema educativo no Brasil, lançado em 1931.
} 
Canuto Mendes elencava uma série de campos de atuação para o gênero cinematográfico educativo, incluindo "a coragem moral e física, disciplina e a ordem". Com base nisso, a declaração do pesquisador pode ser lida como um clamor que fora atendido pelo intervencionismo estatal, anos mais tarde, com a criação do INCE. Isso, pois aquela cinematografia abarcou temas como saúde, educação física, cultura e ciências, sempre permeados pelo civismo.

Os apoiadores da educação religiosa e gerida pelo Estado, católicos como José Alceu de Amoroso Lima e Jonathas Serrano, alertavam, constantemente, para os perigos do cinema comercial, via artigos em periódicos ou correspondências para políticos e membros da burocracia estatal. Alceu Amoroso Lima era aliado político do Ministro Capanema, e, em 1934, quando as discussões sobre a reforma no MES se intensificavam, ele escreveu correspondência ao Ministro enfatizando a necessidade de vinculação dos valores religiosos católicos para a educação pública (SCHWARTZMAN, 1984).

Jonathas Serrano era muito específico quando apontava os problemas morais concernentes ao consumo de filmes Hollywoodianos. Ele enxergava naqueles filmes uma perversa engenharia das almas, promovida, dentre outras coisas, pela naturalização dos cabarés, espaços permissivos, onde as mulheres eram formosas e fáceis, envoltas em sedas e bebendo champanhe (PAULILO, 2002). Assim, o alerta de Serrano recaía, principalmente, sobre a facilidade de consumo dessas fantasias que poderiam confundir valores e introduzir comportamentos que ele julgava condenáveis. Em sua opinião, era necessário impor limites ao que poderia ser assistido pela população, sobretudo jovens, usando o poder persuasivo do cinema em benefício dos valores cristãos, da ordem e da pátria. Seria o cinema contra cinema de Canuto Mendes, ou seja: contra o cinema pernóstico que se faça um cinema cidadão.

Como resposta a esses anseios, foi sancionado o Decreto-Lei número 21.240, de 4 de abril de 1932, que tinha por função nacionalizar o serviço de censura dos filmes cinematográficos, criando uma taxa para a educação popular. Eram componentes, do artigo oitavo do Decreto, regras quanto aos maus exemplos que emanassem dos filmes comerciais e proteção aos credos religiosos, lê-se cristãos, sobretudo, católicos. Outra questão, trazida pelo Decreto, dizia respeito à preservação da dignidade da nação, ou seja, filmes que mostrassem críticas ao Brasil não passariam pelas malhas da censura estatal. A preservação da dignidade nacional, estava ligada a ideia restauradora que a Revolução de 1930 disseminava, enfatizando as potencialidades do Brasil, que foram obscurecidas por gestores da Primeira República, não comprometidos com a nação. Portanto, a missão de 1930 "traduzia a retomada de nossa vocação histórica, a continuação da construção de nossa nacionalidade, integradora de nossa realidade física - nossa terra - e de nosso homem, ambos abandonados e incompreendidos." (GOMES, 2013, p. 193) Nessa perspectiva, os operadores da valorização da terra e do homem brasileiro, por sua vez, deveriam receber o respeito de todos, não estando sujeitos a incitações contra seu prestígio e autoridade, oriundas do cinema. Assim, críticas às autoridades públicas e forças armadas, mesmo que fossem cômicas, a exemplo das construídas por Chaplin, não seriam toleradas.

Art.8 Será justificada a interdição do filme, no todo ou em parte, quando:

I - Contiver qualquer ofensa ao decoro público.

II - For capaz de provocar sugestão para crimes ou maus costumes.

III - Contiver alusões que prejudiquem a cordialidade das relações com outros povos;

IV - Implicar insultos a coletividade ou a particulares, ou desrespeito a credos religiosos.

$\mathrm{V}$ - Ferir de qualquer forma a dignidade nacional ou contiver incitamentos contra a ordem pública, as forças armadas e o prestígio das autoridades e seus agentes. (BRASIL, 1932) 
O teor do artigo oitavo, impôs ao cinema brasileiro o adestramento de suas narrativas, cerceando ideias com vistas à crítica social, por exemplo. No entanto, é preciso observar que as censuras não costumam ser totalmente efetivas, podendo a elas escapar enunciados considerados subversivos. Contudo, em nome de uma fotogenia da nação, o cinema brasileiro acabou tornando-se, o que Paulo Emílio Sales Gomes (2001) considerava colonizado, algo que só seria alterado, efetivamente, no fim da década de 1950, com o Cinema Novo.

Outra questão importante emergia do Decreto de abril de 1932: filmes comerciais que disseminassem, adequadamente, conhecimentos, poderiam ser classificados como educativos, desde que assim fossem reconhecidos pelos membros da comissão de censura. Isso explica o fato de $O$ descobrimento do Brasil $^{14}$, de Humberto Mauro, ter sido considerado educativo, recebendo a chancela da Comissão de censura, ajudando a compor o percentual de filmes educativos determinado pelo próprio Decreto, na grade de programação dos cinemas brasileiros.

$\S 3^{\circ}$ Serão considerados educativos, a juízo da comissão não só os filmes que tenham por objeto intencional divulgar conhecimentos científicos, como aqueles cujo entrecho musical ou figurado se desenvolver em torno de motivos artísticos, tendentes a revelar ao público os grandes aspetos da natureza ou da cultura. (BRASIL, 1932).

Com os recursos advindos dos impostos, arrecadados com a exibição de filmes do circuito comercial, seria construído Órgão estatal, subordinado ao MES, que trataria do estudo do cinematógrafo em suas dimensões técnicas e artísticas. Estava semeado, legalmente, o gérmen do INCE ${ }^{15}$.

Art. 22. No Ministério da Educação e Saúde Pública, dentro da renda da taxa cinematográfica instituída neste decreto, será oportunamente criado um órgão técnico, destinado não só a estudar e orientar a utilização do cinematógrafo, assim como dos demais processos técnicos que sirvam como instrumentos de difusão cultural. (BRASIL, 1932).

A assinatura do Decreto 21.240, que visava "nacionalizar o serviço de censura dos filmes cinematográficos", criando a "Taxa Cinematográfica para a educação popular", pode ser compreendida levando-se em conta os seguintes aspectos: Vargas cedeu às pressões das produtoras de filmes nacionais para que tivessem maior espaço no mercado brasileiro. Vargas via nesse acordo a possibilidade de disseminar o nacionalismo por meio do cinema, presente em boa parte do território nacional. Esse ato ajudaria a fomentar a propaganda política varguista

${ }^{14}$ O DESCOBRIMENTO do Brasil. Direção de Humberto Mauro. EUA: Instituto de cacau da Bahia, 1936. (62 min.), DVD, P\&B.

${ }^{15}$ Não há um número exato a respeito dos filmes produzidos pelo INCE. Estima-se que muitos foram perdidos por falta de armazenamento adequado à sua conservação, já que o material do qual eram feitos era volátil, degradando-se facilmente quando exposto a mínimas alterações de temperatura e umidade. Em 1964, quando Humberto Mauro estava prestes a se aposentar, foram listados 265 filmes restantes no acervo. Esses números também são imprecisos, uma vez que não se sabe se filmes oriundos de outras produtoras e adquiridos pelo INCE foram contabilizados, ou mesmo se entraram na soma filmes não concluídos. No ano de 1966, o INCE deixou de existir, dando espaço ao Instituto Nacional de Cinema (INC). Em 1975, o INC foi extinto e suas demandas, atividades, atribuições e acervo migraram para a Empresa Brasileira de Filmes, a EMBRAFILME. A referida Empresa era uma sociedade de economia mista criada em 1969, da qual o Estado brasileiro também era partícipe. Houve, nesse período, um traço forte de neoliberalis mo na gestão do Estado brasileiro orquestrado pelo Regime Militar cuja consequência foi a diminuição da presença do Estado no segmento da cinematografia educativa, o oposto do que previa a gestão Vargas. 
via cinema, pois o Estado brasileiro passou a apoiar, de maneira mais sistemática, o cinema nacional (SIMIS, 1996). Todas essas questões uniformizadas, respondem às demandas da época para a concepção do cinema educativo, considerando que o supracitado Decreto-Lei foi construído sob a ótica de que o cinema constituía um importante instrumento educativo, civilizador, moralizante e de propaganda política.

\section{Considerações finais}

Os debates sobre a potência do cinema como formatador de ideias já aconteciam antes da criação do INCE, assim como as preocupações com a ressonância das narrativas junto aos jovens e as consequências para a sua educação. Com o intuito de alcançar o maior número possível de estudantes da educação básica da época e até mesmo de adultos, o Estado Brasileiro investiu na construção do Instituto, selecionando como diretor do órgão um indivíduo extremamente comprometido com os saberes científicos em evidência na época. $\mathrm{O}$ cineasta eleito para dirigir a parte técnica do Instituto foi, por muito tempo, um defensor do cinema nacional, sobretudo do gênero documentário, algo evidenciado por meio dos artigos que escreveu para a revista A cena muda. Observa-se ainda, por meio dos excertos da revista A cena muda, que, como periodista, Humberto Mauro, transformou-se em propagador e defensor da gestão do Estado na primeira Era Vargas.

A valorização da cultura e da história do Brasil foi tratada como um meio de propagação de ideais a serem apreendidos pela audiência e também pode ser lida como propaganda política, uma vez que o Estado Novo tinha como eixo norteador o nacionalismo. Tal perspectiva fica evidente se considerarmos a legislação criada com o intuito de estabelecer ligação entre cinema e educação, bem como entre cinema e indústria.

\section{Referências}

ADAMATTI, Margarida Maria. A crítica cinematográfica ao Star System nas revistas de fãs: A Cena Muda e Cinelândia (1952-1955). 2008. 326 f. Dissertação (Mestrado) Curso de Ciências da Comunicação, Escola de Comunicação e Artes, Universidade de São Paulo, São Paulo, 2008.

ALMEIDA, Joaquim Canuto Mendes de. Cinema contra Cinema: bases gerais para um esboço de organização do cinema educativo no Brasil. São Paulo: Cia. Editora Nacional, 1931.

BOURDIEU, Pierre. A ilusão biográfica. In: AMADO, Janaína; FERREIRA, Marieta de Moraes. Usos e abusos da história oral. 8. ed. Rio de Janeiro: FGV, 2006.

BRASIL. Lei $\mathbf{N}^{\circ}$ 378, de 13 de Janeiro de 1937: Dá nova organização ao Ministério da educação e Saúde Pública. DOU, 15 jan. 1937. Seção 1, p. 1210. Disponível em: <http://www2.camara.leg.br/legin/fed/lei/1930-1939/lei-378-13-janeiro-1937-398059publicacaooriginal-1-pl.html>. Acesso em: 07 fev. 2018.

BRASIL. Decreto-lei no 21.240, de 4 de abril de 1932. Nacionalizar o serviço de censura dos filmes cinematográficos, cria a "Taxa Cinematográfica para a educação popular e dá outras providências. Disponível em: http://www2.camara.leg.br/legin/fed/decret/1930-1939/decreto21240-4-abril-1932-515832-norma-pe.html. Acesso em: 07 fev. 2018.

CAPELATO, Maria Helena Rolim. Multidões em cena: propaganda política no varguismo e no peronismo. Campinas: Papirus, 2008. 
FERRO, Marc. Cinema e história. 2. ed. São Paulo: Paz e Terra, 2010.

GOMES, Ângela de Castro. A invenção do Trabalhismo. Rio de Janeiro: FGV, 2005.

GOMES, Ângela de Castro. História e historiadores. Rio de Janeiro: FGV, 2013.

GOMES, Ângela de Castro. Cultura política e cultura histórica no Estado Novo. In: ABREU, Martha; SOIHET, Rachel; GONTIJO, Rebeca. (Org.). Cultura política e leituras do passado: historiografia e ensino de História. Rio de Janeiro: Civilização Brasileira, 2007. p. 43 - 63.

GOMES, Ângela de Castro. A "Cultura História" do Estado Novo. Projeto História: Revista do programa de estudos pós-graduados de História, São Paulo, v. 16, p. 121 - 141, jan./jun. 1998.

MAURO, Humberto. Figuras e Gestos. Revista A cena muda. Rio de Janeiro: Americana, n. 32, p. 22 - 23, 1943.

MAURO, Humberto. Rio de Janeiro: Americana, n. 25, p.22- 29, 1942.

MORETTIN, Eduardo. Humberto Mauro, cinema e História. São Paulo: Alameda Casa Editorial, 2013.

NICHOLS, Bill. Introdução ao documentário. Campinas: Papirus, 2010.

NÓVOA, Jorge (org.). Cinematógrafo, um olhar sobre a história. São Paulo, Salvador: UNESP, EDUFBA, 2009.

PAULILO, André Luiz. A leitura, o cinema e os processos educativos na obra de Jonathas Serrano: problemas metodológicos e precauções morais da pedagogia nos anos 1910-30. História da Educação, v.6, n.11, p.169-192, abr. 2002.

ROSA, Cristina Souza. O ensino de História do Brasil através dos filmes do educativos do INCE, durante o Estado Novo. In: XII ENCONTRO REGIONAL DE HISTÓRIA ANPUH, 12., 2006, Niterói. Anais... Rio de Janeiro: ANPUH, 2006. Disponível em: http://www.rj.anpuh.org/ resources/rj/Anais/2006/conferencias/CristinaSouzadaRosa.pdf. Acesso em: 09 fev. 2018.

ROSA, Cristina Souza. Para além das fronteiras nacionais: Um estudo comparado entre os Institutos de Cinema Educativo do Estado Novo e do Fascismo (1925-1945). 395 f. Tese (Doutorado) - Curso de História, Ciências Humanas, Universidade Federal Fluminense, Niterói, 2008.

SALES GOMES, Paulo Emílio. Cinema, trajetória no subdesenvolvimento. Rio de Janeiro: Paz e Terra, 2001.

SALIBA, Maria Eneida Fachini. Cinema contra cinema. O cinema educativo de Canuto Mendes (1922-1931). São Paulo: Annablume - FAPESP, 2003.

SCHVARZMAN, Sheila. Humberto Mauro e as imagens do Brasil. São Paulo: UNESP, 2004. DOI: https://doi.org/10.7476/9788539303137. 
SCHWARTZMAN, Simon. Educação e Cultura no Regime Vargas: A Revolução de 30. Brasília: UNB,1984.

SCHWARTZMAN, Simon; BOMENY, Helena; COSTA, Vanda. Tempos de Capanema. Rio de Janeiro: Paz e Terra. São Paulo: EDUSP, 1984.

SERRANO, Jonathas. Como se ensina História. São Paulo: Melhoramentos, 1935.

SERRANO, Jonathas; VENANCIO, Filho Francisco. Cinema e educação. São Paulo: Melhoramentos, 1930.

SILVA, Cristiani Bereta da (org.). Educar para a nação: cultura política, nacionalização e ensino de História nas décadas de 1930 e 1940. Curitiba: CRV, 2014.

SIMIS, Anita. Estado e cinema no Brasil, São Paulo: Annablume, 1996.

VIANY, Alex. Humberto Mauro: Sua vida, sua arte, sua trajetória no cinema. Rio de Janeiro: Arte nova, 1978. 